\title{
Environmental Performance, Environmental Disclosure and the Role of media
}

\author{
Yue Zhang ${ }^{\mathrm{a}}$, Changjiang Zhang ${ }^{\mathrm{b}}$ \\ School of Economics and Management, Nanjing Tech University, Nanjing 211816, China \\ a'Moonnzhang@163.com, bzcj361@163.com
}

Keywords: environmental performance, environmental disclosure, media

\begin{abstract}
With the continuous advancement of ecological civilization construction, enterprises are increasingly inclined to transmit good information on environmental management to external stakeholders through environmental disclosure, using media to shape the green image and establish corporate reputation. This study analyzes the panel data of 148 listed companies in China's A-share heavy polluting industry as a research sample from 2012 to 2016, empirically tests the impact of corporate environmental performance on environmental disclosure, and analyzes the role of media in these two. The results reveal that there is a positive correlation between environmental disclosure and environmental performance of listed companies in heavy polluting industries. What's more significant, media attention has a positive adjustment effect.
\end{abstract}

\section{Background}

Nowadays, green development and ecological economy are increasingly valued. The report of the 19th National Congress of the Communist Party of China has raised the construction of ecological civilization to the strategic height of "the millennium plan for the sustainable development of the Chinese nation." However, at present, air pollution, water pollution, land desertification, soil erosion and other conditions emerge one after another, undoubtedly exposed the seriousness of environmental problems. When the "Zijin Mining" incident was still suffering from the shock, the heavily damaged of Qilian Mountain once again sounded the alarm bell. For enterprises in heavy polluting industries, they will face more environmental management problems. Government has promulgated relevant laws and regulations, trying to build a mandatory environmental disclosure system to change the status quo. More and more listed companies are expected to disclose environmental information in their annual reports or publish separate reports to show their practices of environmental protection, enhancing environmental reputation.

With the popularization of digital network and mobile communication technology, media has become the main medium of information dissemination. According to the theory of "Agenda Setting", media plays the role of guiding public opinion in the construction of corporate social responsibility. Enterprises fulfill their environmental responsibilities, fully disclose relevant environmental information, and enables the stakeholders to fully understand the environmental management status of the enterprise. Through media transmission, the daily operation of the enterprise will be more transparent, taking the road of environmentally sustainable development, so as to alleviate the bad environmental pollution. Therefore, enterprises tend to report positive information of their environmental behaviors through media, assume important environmental responsibilities, meet the needs of stakeholders, and thus gain wide public support.

\section{Theoretical analysis and research hypothesis}

\section{Environmental disclosure and environmental performance}

Different companies have great differences in environmental disclosure, and scholars hold different views on why companies are willing to provide environmental information (Kolk, 2003; Patten, 2002; Russo \& Fouts, 1997). Essentially, there are two theories that can explain this phenomenon: legitimacy theory and voluntary disclosure theory. 
Legitimacy theory believes that information disclosure is a reflection of the social pressure and political pressure. To some extent, companies with poor environments performance face more pressures which have threaten their legitimacy, hence they'll try to increase discretionary environmental disclosures to change stakeholder perceptions. Therefore, companies with low environmental performance are more willing to disclose information, and environmental performance and environmental disclosure are negatively correlated. Voluntary disclosure theory emphasizes that companies with good environmental performance are willing to provide more environmental information and shape green brands. Enterprises with relatively poor environmental performance can only choose to reduce disclosure or "keep silent" so as to cut down negative impacts. In order to avoid adverse selection, the company intends to disclose "good news" and distinguish itself from companies with "bad news" (Verrecchia, 1983). A company with good performance attempts to directly convey the information to investors and other stakeholders by directly revealing objective performance, truly demonstrates the environmental management of the company, which is difficult for enterprises with poor environmental performance to imitate.

With the continuous advancement of ecological civilization construction, good environmental performance can bring green premium to environmentally-friendly enterprises. Customers are willing to purchase green products from companies with good environmental performance at a higher price, and the improvement in business performance has prompted these companies to have the incentive to disclose more environmental information. At the same time, good performance can help to enhance the public image and reputation, build brand competitive advantage, gain social recognition, and win government support related to environmental protection (Liu \& Anbumozhi, 2009). It is particularly prominent in China, where the government can provide incentives such as environmental incentives, refinancing facilities, tradable permits and green credit policies. Inspired by fiscal policy and monetary policy, companies with good environmental performance will disclose more information. Conversely, if a company with poor environmental performance reveals false data for whitewashing its behavior, it may lead to resentment and rejection by the public and even severe punishment by the government. In order to stay safe, companies tend to cover up information. Therefore, we expect the following:

H1. Environmental disclosure is positively associated with environmental performance.

\section{The role of media}

Media plays an important role in external governance, so it is necessary to examine the impact of media concerns on the relationship between environmental performance and environmental disclosure. Theory shows that media can effectively improve the level of environmental disclosure of enterprises through information dissemination mechanisms and supervision mechanisms. Dyck (2008) pointed out that the governance function of media is to effectively reduce information asymmetry through information transmission, which is widely recognized by the academic community. From the perspective of stakeholders, media is a mirror which can reflect reality. On the one hand, disclosure of environmental management information can reduce the concern for corporate uncertainty, on the other hand help to cut down costs for information search and improve resource allocation efficiency. For companies, they use media to attract public attention and enhance the public's perception of corporate social image through reputational mechanisms. Bloomfield et al. (2000) found that the company's environmental disclosure level improved as the number of media reports increased.

As an invisible external pressure, media also has independent supervision and control power for the company (Porter \& Kramer, 2006). According to the agenda setting theory, media coverages record the opinions of the public as an active force that independently influences the process of social interaction and value formation. Through setting the public agenda, it tends to exert pressure on enterprises. Based on reassessing public expectations, companies disclose more information as a passive strategic response to media concerns. Thus, under the supervision of the public and public opinion, in order to prevent negative image and strengthen positive image, companies will strive to fulfill their actions in line with stakeholder needs and corporate governance guidelines when formulating strategies, focusing on green development and environmental technology innovation. Also, they will have good performance in environmental disclosure. Therefore, under a certain level 
of environmental performance, the presence of media will encourage companies to disclose more environmental information. The hypothesis that is tested is as follows:

H2. Media plays a positive role in regulating the relationship between environmental performance and environmental disclosure.

\section{Methods}

\section{Dataset}

This study focuses on companies that are listed on Companies' Environmental Verification Industry Classification Management (Environmental Circular Letter [2008] No. 373) and the Guide for Environmental Disclosure of Listed Companies (Environmental Circular Letter [2010] No. 78). The period of investigation is 2012 to 2016. China's heavily polluting industry A-share listed companies are selected as samples. After eliminating incomplete data, it finally included 740 observations of 148 enterprises. Information on environmental disclosure and environmental performance have been collected from company annual reports, social responsibility report and company websites. The data of media comes from the CNKI important newspaper database.

\section{Dependent variable}

Content analysis is used to measure environmental disclosure. According to the standard disclosure on environmental aspects proposed in the "Guidelines for the Compilation of China's Corporate Social Responsibility Report", the measurement indicators are divided into three parts (thirty indicators) which including environmental management, resource \& energy conservation, and pollution \& emission reduction. If the corresponding content is mentioned in the social responsibility report or the sustainability report, assign 1 point. In order to avoid subjectivity when scoring, two people score and summarize separately. If there is a significant difference, a third person will coordinate.

\section{Independent variables}

Since micro-data at the enterprise level is difficult to obtain, previous studies have not yet formed a unified standard to measure the environmental performance of listed companies. There is no clear environmental performance ranking in China, nor is there a database of environmental performance related to the Toxic Substances Inventory (TRI). Some scholars use AHP to comprehensively quantify multiple environmental indicators (HT Shen, J Feng, 2012; WB Long et al., 2015). However, this valuation method has certain subjectivity. Patten (2005) pointed out that corporate environmental capital expenditure is a relatively accurate objective environmental performance indicator. WJ Li and XY Lu (2015) have also used environmental capital expenditure to measure corporate environmental performance. This paper draws on the above practices, taking the ratio of the company's environmental capital expenditure to the total assets at the end of the year as an indicator of environmental performance.

The media data comes from the CNKI national important newspaper database, covering relevant reports of more than 500 prefecture-level and above-level newspapers and periodicals in China (PG Li and YF Shen, 2010). Search the database for news containing sample company names and words such as "ecology", "environmental protection", "environment", "green", etc. Each article receives 1 point for the company's media reports. In order for the indicator to not score 0 , construct the media variable: Media $=$ Ln (company media coverage +2 ). This paper argues that both positive and negative reports can expose companies to stakeholders clearly, and thus do not distinguish between positive and negative reports from an emotional perspective.

\section{Control variables}

Previous research has indicated that company size, financial leverage, growth phrase, ownership structure, property rights, and profitability can affect disclosure practices. Hence, we formed additional independent variables as control variables. 
Table 1 Measurement of control variables.

\begin{tabular}{ccc}
\hline Variable & Name & Measurement \\
\hline Company size & SIZE & Ln(Total assets) \\
Financial leverage & LEV & Total liabilities / Total assets \\
Growth phrase & GR & The rate of operating income increase \\
Ownership structure & LAR & The shareholding ratio of the largest shareholder \\
Property rights & GOV & State-owned enterprises is 1, otherwise 0 \\
Profitability & ROA & Net profit / Total assets \\
\hline
\end{tabular}

\section{Model}

According to the previous analysis, set the model to:

Model 1:EDI $=\propto+\beta_{1} S I Z E+\beta_{2} R O A+\beta_{3} L E V+\beta_{4} G R+\beta_{5} L A R+\beta_{6} G O V+\varepsilon$

Model 2:EDI $=\propto+\beta_{1} E P+\beta_{2} S I Z E+\beta_{3} R O A+\beta_{4} L E V+\beta_{5} G R+\beta_{6} L A R+\beta_{7} G O V+\varepsilon$

Model 3: EDI $=\propto+\beta_{1} E P+\beta_{2}$ Media $+\beta_{3} S I Z E+\beta_{4} R O A+\beta_{5} L E V+\beta_{6} G R+\beta_{7} L A R+$ $\beta_{8} G O V+\varepsilon$

Model 4: EDI $=\propto+\beta_{1} E P+\beta_{2}$ Media $+\beta_{3}$ Media $* E P+\beta_{4}$ SIZE $+\beta_{5} R O A+\beta_{6} L E V+$ $\beta_{7} G R+\beta_{8} L A R+\beta_{9} G O V+\varepsilon$

Four econometric models are constructed to verify the hypotheses we proposed. To verify the link between ERs and EP, the linear regression model shown in Model 1,2 is used. In order to verify Hypothesis 2, whether media will play a linear adjustment role in the process of environmental performance affecting environmental disclosure, model 3,4 is constructed.

\section{Results}

\section{Descriptive statistics}

Table 2 Descriptive statistics.

\begin{tabular}{cccccc}
\hline Name & N & Mean & SD & Min & Max \\
\hline EDI & 740 & 7.441892 & 3.974292 & 0 & 21 \\
EP & 740 & .4222573 & .8483257 & 0 & .6796 \\
Media & 740 & 1.403291 & .823024 & .69315 & 4.61512 \\
SIZE & 740 & 22.81919 & 1.955959 & 11.3859 & 26.458 \\
LEV & 740 & 47.52549 & 20.74861 & 1.397 & 103.7263 \\
GR & 740 & 6.847423 & 29.09312 & -55.9238 & 334.6871 \\
LAR & 740 & 39.82468 & 16.4194 & -22.71 & 160.69 \\
GOV & 740 & .6472973 & .4781343 & 0 & 1 \\
ROA & 740 & 5.170797 & 13.05873 & -22.7117 & 220.6264 \\
\hline
\end{tabular}

Table 3 Correlation coefficients of all variables.

\begin{tabular}{cccccccccc}
\hline & EDI & EP & Media & SIZE & LEV & GR & LAR & GOV & ROA \\
\hline EDI & 1 & & & & & & & & \\
EP & $0.2433^{* *}$ & 1 & & & & & & \\
Media & $0.3407^{* *}$ & $0.0841^{*}$ & 1 & & & & & \\
SIZE & 0.0198 & $-0.1543^{* *}$ & 0.0483 & 1 & & & & \\
LEV & $0.1501^{* *}$ & 0.0272 & $0.3037^{* *}$ & $0.3591^{* *}$ & 1 & & & \\
GR & $-0.1014^{* *}$ & 0.0084 & $-0.1617^{* *}$ & -0.0202 & -0.0009 & 1 & & \\
LAR & $0.1419^{* *}$ & $0.0894^{*}$ & $0.2848^{* *}$ & -0.0270 & $0.1457^{*}$ & $-0.1080^{* *}$ & 1 & \\
GOV & $0.1384^{* *}$ & -0.0439 & $0.2607^{* *}$ & $0.1082^{* *}$ & $0.2522^{*}$ & $-0.1216^{* *}$ & $0.3075^{* *}$ & 1 & \\
ROA & -0.0389 & -0.0370 & $-0.0581^{*}$ & 0.0036 & -0.2121 & $0.1346^{* *}$ & $0.1069^{* *}$ & $-0.1844^{* *}$ & 1 \\
\hline
\end{tabular}

$* \mathrm{p}<0.05, * * \mathrm{p}<0.01$

Table 2 presents the descriptive statistics for the variables used in the empirical analysis. It can be seen that the average of EDI for explanatory variables in 740 samples is 7.4418 . The maximum is 0 and minimum values is 21 ; indicating that the quality of environmental disclosure of listed companies in China's heavily polluting industries is uneven at this stage. Most companies have a weak awareness 
of information disclosure. The average of EP is 0.4223 . The maximum and minimum values are 0 and 0.6796 respectively. The large difference reflects that current investment level of Chinese enterprises for environmental protection is generally low. In addition, the average value of media is 1.403 , indicating that heavy polluting industry companies are not well received by the media; the minimum value of 0.69315 and the maximum value of 4.61512 shows that different listed companies are subject to greater differences in media coverage. Table 3 shows that EDI and EP has a significant positive correlation at the $1 \%$ level, which is consistent with Hypothesis 1 . At the same time, media and EDI are significantly correlated at the 1\% level, indicating that media has a certain influence on EDI, which provides the basis for further data analysis.

\section{Empirical findings}

In order to test the impact of environmental performance on environmental disclosure, based on model 1, 2, EDI is added to the independent variable, and the regression equation $F$ value is 12.359 $(p<0.01)$, and the regression equation is significant. The regression coefficient of EDI is significantly positive $(\beta=0.241, \mathrm{p}<0.01)$, indicating that the higher the environmental performance of enterprises, the more likely they are to disclose more environmental information. The result verifies hypothesis 1. The interaction term between media attention and environmental performance is introduced into the regression equation, It is found that the explanatory power of the model has improved. The adjusted R2 is 0.183 , which is significant at the level of $1 \%$. The media's regression coefficient of interaction with environmental performance is significantly positive $(\beta=0.307, p<0.01)$, indicating that media plays a positive role in environmental performance and environmental disclosure. Therefore, Hypothesis 2 is also supported.

Table 4 Regression results

\begin{tabular}{ccccc}
\hline & \multicolumn{4}{c}{ Dependent variable: EDI } \\
\cline { 2 - 5 } & Model 1 & Model 2 & Model 3 & Model 4 \\
\hline Constant & 6.666 & 4.568 & 3.383 & 3.423 \\
SIZE & -0.035 & .007 & .021 & $0.719^{*}$ \\
LEV & $.132^{* * * *}$ & $.112^{* * *}$ & .036 & 0.041 \\
GROW & $-.084^{* *}$ & $-.087^{* *}$ & -.050 & -0.056 \\
LAR & $.090^{* *}$ & $.065^{*}$ & .013 & 0.005 \\
GOV & $0.072^{*}$ & $.092^{* *}$ & .054 & 0.051 \\
ROA & 0.004 & .016 & .009 & 0.007 \\
EP & & $.241^{* * *}$ & $.224^{* * *}$ & $0.187^{* * *}$ \\
Media & & & $.284^{* * *}$ & $0.256^{* * *}$ \\
EP*Media & & & & $0.307^{* * *}$ \\
F & $6.458^{* * *}$ & $12.359^{* * *}$ & $18.883^{* * *}$ & $19.285^{* * *}$ \\
Pseudo R & 0.042 & 0.097 & 0.162 & 0.183 \\
\hline
\end{tabular}

$* \mathrm{p}<0.10, * * \mathrm{p}<0.05, * * * \mathrm{p}<0.01$

In the adjustment effect model of environmental performance as an independent variable, media attention is divided into three levels: high, medium and low according to the mean and mean plus or minus one standard deviation. When environmental performance interacts with medium-level or high-level media attention, its regulation effect is significant. The adjustment effect values are 0.8770 and 1.4272. The confidence intervals are $(0.5541,1.2000),(1.0696,1.7848)$, and 0 is not included. When the environmental performance interacts with low-level media attention, the confidence interval is $(-0.0262,0.8309)$, which including 0 , thus the adjustment effect is not significant. Therefore, media plays a positive role in the adjustment of environmental performance and environmental disclosure.

Table 5 Specific performance of the adjustment effect

\begin{tabular}{ccccccc}
\hline Media & Effect & $\mathrm{se}$ & $\mathrm{T}$ & $\mathrm{p}$ & LLCI & ULCI \\
\hline High & 1.4272 & 0.1822 & 7.8353 & 0.0000 & 1.0696 & 1.7848 \\
Medium & 0.8770 & 0.1645 & 5.3312 & 0.0000 & 0.5541 & 1.2000 \\
Low & 0.4023 & 0.2183 & 1.8433 & 0.0657 & -.0262 & 0.8309 \\
\hline
\end{tabular}




\section{Conclusions}

This paper explores the impact mechanism of corporate environmental performance on environmental disclosure, focusing on the role of media. By taking the 2012-2016 A-share listed company in China's heavy polluting industry as a sample for regression analysis, it is found that: (1) Environmental disclosure is positively associated with environmental performance. That is, the higher the corporate environmental capital expenditure represents the better environmental performance, the more inclined to disclose more environmental information. In order to convey the advantages to stakeholders, companies will truly show the environmental management information to distinguish them from others to gain market competitiveness. (2) Media plays a positive role in the relationship between corporate environmental disclosure and environmental performance. Under certain environmental performance, the level of corporate environmental disclosure will be significantly improved with media attention. Environmental disclosure is a powerful way for enterprises to communicate environmental management information to the external public. Enterprises can also use the media platform to publicize their environmental protection concepts, environmental protection investment and other information, increase stakeholder awareness and establish a good green reputation.

In the era of big data, to a certain extent, media has played the role of "magnifying glass" and "sound tube". It is supposed to show its corporate governance function, supervise every move of the enterprise, and constrain the non-environmental behavior. The government should pay more attention to the positive role of media, introduce corresponding policies and regulations to regulate the development of media, construct a good platform for enterprises to disclose information, and also build a harmonious public opinion environment for the development of ecological civilization.

\section{References}

[1]Verrecchia R E. Discretionary disclosure [J]. Journal of Accounting \& Economics, 1983, 5(1):179194.

[2]Liu X, Anbumozhi V. Determinant factors of corporate environmental information disclosure: an empirical study of Chinese listed companies[J]. Journal of Cleaner Production, 2009, 17(6):593-600.

[3]Dyck , Alexander , Natalya Volchkova , and Luigi Zingales , 2008, “The Corporate Governance Role of the Media : Evidence from Russia”, Journal of Finance,63,pp.1093-1136.

[4]Bloomfield R J, Wilks T J. Disclosure Effects In The Laboratory: Liquidity, Depth, And The Cost Of Capital[J]. Social Science Electronic Publishing, 2000, 75(1):13-41.

[5]Porter M E, Kramer M R. Strategy and society: the link between competitive advantage and corporate social responsibility[J]. Harv Bus Rev, 2006, 84(12):78-92.

[6]Clarkson P M, Li Y, Richardson G D, et al. Revisiting the relation between environmental performance and environmental disclosure: An empirical analysis[J]. Accounting Organizations \& Society, 2008, 33(4-5):303-327.

[7]HT Shen, J Feng. Media Monitoring, Government supervision and Corporate Environmental Disclosure [J]. Accounting Research, 2012 (02): 72-78

[8]WB Long, SH Li, XZ Song. Environmental Regulation and the Environmental Performance of Small and Medium-sized Enterprises(SMES): Evidence from the SME Board and Griwth Enterprise Board Listed Companies in China [J]. Journal of Public Administration, 2015, 8(06): 25- 58

[9]WJ Li, XY Lu. Do Institutional Investors Care Firm environmental performance? Experience from the Most Polluting Chinese Listed Firms [J]. Journal of Financial Research,2015(12):97-112.

[10]PG Li, YF Shen. The Corporate Governance Role of Media: Empirical Evidence from China[J]. Economic Research Journal, 2010, 45(04): 14-27. 